\title{
Trend analysis of statistically downscaled precipitation for tropical semi-arid climate
}

\author{
Kanhu Panda ${ }^{1,2}$, Laxmi Thakural ${ }^{3}$, and Ram Singh ${ }^{2}$ \\ ${ }^{1}$ Banaras Hindu University \\ ${ }^{2}$ Banaras Hindu University Institute of Agricultural Sciences \\ ${ }^{3}$ National Institute of Hydrology
}

September 16, 2020

\begin{abstract}
The coarse resolution climatic data extracted from the global climate models (GCM) cannot be utilised straightaway for research works on climate change impact analysis. Thus, the downscaling technique is used to attain a higher resolution scenario from the GCM. In the current study, the Canadian Centre for Climate Modelling and Analysis (CCCma)-GCM is used to predict monthly precipitation using the statistical downscaling technique for the tropical semi-arid region of Eastern Gujarat for the period 2019-2099. Geo-potential height (h500) and mean sea level pressure (MSLP) are chosen as explanatory variables for the downscaling model. The model is developed using the principal component analysis (PCA) - multiple linear regression (MLR) combined approach. The model is applied to predict rainfall for three representative concentration pathway (RCP) scenarios, RCP2.6, RCP 4.5, and RCP 8.5. The best-suited scenario for the study area is selected using robust statistical indicators such as the Nash-Sutcliffe efficiency and the root mean square error. Several parametric and nonparametric tests are conducted to analyse rainfall trends in the Eastern Gujarat region. The outcomes showed that the precipitation scenario produced for RCP4.5 replicates the climatology of the region suitably. The trend investigation of the predicted rainfall showed that the significance of the seasonal trend is independent of the significance of monthly trends. Trend analysis of downscaled precipitation series can report multiple change points for a region. Further, the annual rainfall increases tremendously in the tropical semi-arid regions over the 21st century. This study will provide insights into sustainable water resource management and development.
\end{abstract}

Title : Trend analysis of statistically downscaled precipitation for tropical semi-arid climate

Running title : Trend analysis of downscaled rainfall

Authors

Kanhu Charan Panda ${ }^{1}$ | L. N. Thakural ${ }^{2}$ | R. M. Singh ${ }^{1}$

${ }^{1}$ Institute of Agricultural Sciences, BHU, Varanasi, UP, 221005, India

${ }^{2}$ National Institute of Hydrology, Roorkee, Uttarakhand, 247667, India

Correspondence

Kanhu Charan Panda, Institute of Agricultural Sciences, BHU, Varanasi, UP, 221005, India

Email: kanhucharan.bm@gmail.com

\section{Acknowledgements}

We thank Prof. V.K. Chandola, Prof. A.K. Nema, Dr. V.K. Tripathi and Dr. Abhishek Singh from Department of Farm Engineering, Institute of Agricultural Sciences, Banaras Hindu University, for their 
support throughout the research. We also express our gratitude to the director of the National Institute of Hydrology, Roorkee for the facilities provided for the study.

\section{Hosted file}

main document.docx available at https://authorea.com/users/355183/articles/481349-trendanalysis-of-statistically-downscaled-precipitation-for-tropical-semi-arid-climate

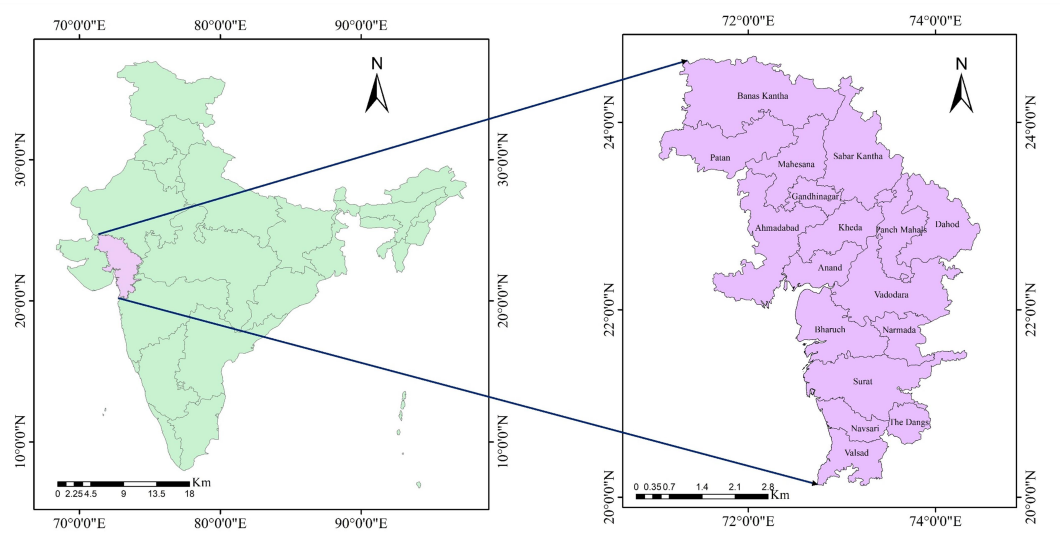

FIGURE 1 Index map of Eastern Gujarat 